\title{
Muriel Guittat-Naudin, Pie XII après Pie XII. Histoire d'une controverse
}

Éditions de l'EHESS, coll. « Cas de figure », 2015, 339 p.

\section{Benjamin Fabre}

\section{(2) OpenEdition}

\section{Journals}

Édition électronique

URL : http://journals.openedition.org/assr/28244

DOI : $10.4000 /$ assr.28244

ISSN : $1777-5825$

Éditeur

Éditions de l'EHESS

Édition imprimée

Date de publication : 31 décembre 2016

Pagination : 318

ISSN : 0335-5985

Référence électronique

Benjamin Fabre, " Muriel Guittat-Naudin, Pie XII après Pie XII. Histoire d'une controverse », Archives de sciences sociales des religions [En ligne], 176 | octobre-décembre 2016, mis en ligne le 18 juillet 2017, consulté le 24 septembre 2020. URL : http://journals.openedition.org/assr/28244 ; DOI : https:// doi.org/10.4000/assr.28244

Ce document a été généré automatiquement le 24 septembre 2020.

(c) Archives de sciences sociales des religions 


\section{Muriel Guittat-Naudin, Pie XII après Pie XII. Histoire d'une controverse}

Éditions de l'EHESS, coll. « Cas de figure », 2015, 339 p.

\section{Benjamin Fabre}

\section{RÉFÉRENCE}

Muriel Guittat-Naudin, Pie XII après Pie XII. Histoire d'une controverse, Éditions de l'EHESS, coll. « Cas de figure », 2015, $339 \mathrm{p}$.

1 Comme le dit à plusieurs reprises Muriel Guittat-Naudin, aussi longtemps que les archives du Vatican concernant le temps de la Seconde Guerre mondiale ne sauront pas complètement accessibles, on ne pourra pas vraiment connaître toutes les conditions du silence du pape Pie XII en face du massacre des juifs par l'Allemagne nazie. Aussi bien ne cherche-t-elle pas à prononcer sur ce pénible chapitre un verdict ou un jugement définitif. Son propos est plutôt de suivre les réactions suscitées par cet aspect du pontificat du pape Pacelli dans le monde et dans l'opinion catholique. En même temps qu'elle en suit les mouvements en liaison avec ceux de la situation politique mondiale depuis 1945, l'auteur retrace aussi - et ce n'est pas le moindre intérêt de son travail - l'évolution de l'image et du mythe du "pape », une sorte de démythification qui pourrait se poursuivre d'ailleurs aujourd'hui autour du pape François.

2 Pour des raisons que le Vatican s'est efforcé de montrer bonnes, le pape Pie XII s'est tu devant le génocide nazi. Il faut bien appeler silence l'absence d'une condamnation claire et vigoureuse, compréhensible et saisissable immédiatement par tous, comme les papes divers ont su le faire en face du communisme athée ou des persécutions dont furent victimes les chrétiens en Chine ou ailleurs. La lettre encyclique de Pie XI en 1938 Mitt brennender Sorge (que l'on peut traduire par: «Dans un souci brûlant») où le prédécesseur de Pie XII condamnait le nazisme avant même que ses crimes ne soient perpétrés et connus fut la dernière prise de position nette du Vatican devant l'hitlérisme. 
3 La guerre finie, les autorités romaines ont évoqué l'aide apportée par le Vatican aux juifs persécutés. Aide discrète, parfois efficace, qui a suffi souvent - la même prétention fut utilisée par d'autres en d'autres lieux à la même époque - à justifier les silences du pape, comme si ceux-ci témoignaient d'une prudence précautionneuse permettant à d'autres actions positives de s'exercer. On tenta aussi de trouver des intentions habilement manifestées et cachées tout à la fois dans telle ou telle déclaration papale. Non sans quelque roublardise, pour ne pas dire plus. Ainsi lit-on dans la Nouvelle Revue Théologique en mars 1945 à propos du message de Noël de Pie XII en 1942: «il est impossible de lire ces lignes sans penser aux terribles mesures contre les juifs décrétées et exécutées par l'Allemagne en ces années 42 et 43.» Mais si c'était peut-être impossible en relisant « ces lignes » en 1945, pouvait-on " penser » au génocide en les lisant en 42 , alors que celui-ci n'était pas encore, loin de là, connu de tous. Le déchiffrage facile de tel ou tel texte en 1945 ne l'empêche pas d'avoir été bien secret en 42 ou 43.

4 Le « concert de louanges » auquel se joignit aussi alors une bonne partie de l'opinion juive ne fut pourtant pas unanime. Albert Camus par exemple, dans Combat en décembre 1944, François Mauriac en novembre de la même année, émettaient quelques doutes. Paul Claudel lui-même évoquait «l'affreux silence du Vatican». Certains ne parlaient pas seulement d'un silence, mais allaient jusqu'à penser que l'anticommunisme, et même l'antisémitisme latent des catholiques, pouvaient éclairer la réserve de Pie XII. Muriel Guittat-Naudin rappelle qu'en 1947 encore Monseigneur Guéry, évêque auxiliaire de Grenoble, pouvait justifier la législation antisémite de Vichy par le problème " posé par l'existence, au sein d'une nation, d'une communauté qui a résisté à toute assimilation [...]. L'État a le droit et le devoir d'exercer une vigilance active afin que la persistance de cette unité ne porte pas préjudice au bien commun de la nation» (p. 64). Si, en 1945, le pape parut lui-même s'interroger («aurait-il été possible alors, par des mesures politiques opportunes et adaptées, de freiner une fois pour toutes le déchaînement de la violence brutale et de mettre le peuple allemand en état de se dégager des tentacules qui l'étreignaient», p. 65), le climat de la guerre froide conforta le prestige et l'autorité de Pie XII jusqu'à sa mort en 1958.

5 La disparition du pontife silencieux semble avoir réveillé le débat étouffé depuis de nombreuses années. Mais il faut attendre 1963 et la représentation à Berlin du Vicaire de Rolf Hochhuth pour qu'une "affaire Pie XII » soit définitivement lancée. On se rappelle l'origine de cette pièce de théâtre : le SS Kurt Gerstein a effectivement tenté d'informer le Vatican par la nonciature de Berlin sur les camps d'extermination en Pologne. Il s'est heurté à l'indifférence, voire à l'hostilité du Vatican et de Pie XII luimême. Traduite en 17 langues, adaptée au théâtre dans 27 pays (et récemment au cinéma par Costa Gavras dans Amen) la pièce provoque des réactions brutales et des polémiques où se "fracasse ", écrit Muriel Guittat-Naudin, l'image positive de Pie XII. Évoquant les critiques qui s'élèvent alors, l'auteur les qualifie en passant de «tonitruantes". Le mot n'est pas aimable, mais soit: ces critiques deviennent alors vives et vont s'intensifiant. Le langage des défenseurs est en effet plus mesuré, mais dans les formes ecclésiastiques, il reste tout de même fort : ainsi Monseigneur Feltin, archevêque de Paris : «quand ce pape est aussi grand que le fut Pie XII, quand il s'agit de cet inlassable défenseur de la personne humaine, de la paix et de la justice au milieu de la passion déchaînée de la guerre et de la persécution raciale, un honnête homme ne peut que réprouver la légèreté de certaines caricatures » (p. 141). La pièce Le vicaire, dit 
le cardinal Spellman, archevêque de New York, est "diffamatoire et sacrilège », elle " outrage l'honneur d'un homme grand et bon ». Ce n'est pas " tonitruant », mais tout de même...

6 Autant où se jouait un peu partout ce Vicaire, s'ouvrait le concile Vatican II. Muriel Guittat-Naudin remarque qu'un nouveau visage de la papauté succède à la figure autoritaire et hiératique de Pie XII, le visage de Jean XXIII, plus proche et moins mystérieux. L'auteur du livre, lorsqu'elle souligne le changement alors intervenu, omet de rappeler les bruits étranges qui avaient accompagné les derniers mois de Pie XII : celui-ci aurait vu, selon le cardinal Tedeschino, le soleil effectuer dans le ciel une bizarre chorégraphie. Dernière tentative peut-être pour dilater le prestige du pape Pacelli. Jean XXIII et Paul VI changent de ton et de perspective, l'Église s'engage avec eux dans les affaires temporelles, et ce nouvel esprit fait de Pie XII et de son silence les témoins d'une époque révolue. La présence d'une parole pontificale face aux problèmes économiques et sociaux qui agitent notre monde dans leur actualité et leur événementialité même rend peu compréhensibles les prudences diplomatiques du Vatican pendant et après la guerre. Elle transforme aussi le regard que les catholiques portent sur ce qui fut longtemps le chef couronné de leur Église et aussi l'image que les non-catholiques se font d'un homme dont la parole concerne aussi ceux qui ne partagent pas sa foi. Finalement, la mise en cause des positions d'un pape controversé n'a pas affaibli, mais au contraire contribué à renforcer l'autorité morale et même spirituelle, d'une voix qui n'est pas étouffée par le recul de la vie religieuse dans le monde moderne. 